\title{
A Inserção de Atividades Experimentais no Ensino de Ciências em Nível Médio: Um Relato de Sala de Aula
}

\section{The Insertion of Experimental Activities in the Teaching of Sciences in Middle Level: A Report of Classroom}

Denise Celeste Godoy de Andrade Rodrigues ${ }^{1}$

\section{Resumo}

A experimentação atua como mola-mestra no ensino de ciências, servindo para demonstração de fatos e conceitos científicos,bem como para despertar a curiosidade dos alunos e para incentivar novas descobertas. Neste trabalho foi montada uma feira de ciências, como parte da disciplina de atividades complementares, em colaboração com alunos do primeiro ano do ensino médio de uma escola pública, do município de Resende, no interior do Estado do Rio de Janeiro. O projeto desenvolvido mostrou-se eficaz na melhoria do aprendizado da disciplina de Física, sendo aplicável em qualquer sala de aula, com baixo custo e sem necessidade de uma sala especial ou de um laboratório específico para este fim. O envolvimento dos alunos foi imprescindível para a realização deste estudo.

Palavras-chave: Experimentação; ensino de Ciências; Física.

\section{Abstract}

The difficulty of understanding what is written under the eyes and of writing what is in mind clearly is the problem of dyslexic. Receiving information through reading becomes impossible, completely or in bigger or smaller grades. Dyslexic cannot understand the message of understand it badly, inferring a modified meaning. Yet, helshe cannot put on paper his/her thoughts, or puts on paper but in such incorrect way of words graph that it is impossible the comprehension of the subject. Dyslexic many times can be more intelligent than the average of students and helshe stays apart from his/her environment from the moment helshe goes to school and his/her problem appears. It is believed that there are at least ten dyslexics among a hundred individuals, that is why is so urgent that we know about this subject. There is a treatment which can help dyslexics to overcome their difficulties and, in a practical point of view, to go to the equals group, using reasonably reading and writing.

Keywords: Experimentation; teaching of Sciences; Physics. 


\section{INTRODUÇÃO}

Como professora de Fìsica no ensino médio, venho observando as dificuldades e falta de interesse por parte dos alunos pelas disciplinas de ciências. Para muitos alunos, o preconceito em relação às disciplinas de ciências, pricipalmente Física, faz com que estes tenham verdadeiro pânico perante os professores, principalmente por associarem a esta disciplina fórmulas matemáticas (RICARDO e FREIRE, 2007).

Segundo Ricardo e Freire (2007) o ensino médio é o nível escolar que mais sente as mudanças sociais, pois sua conclusão coincide com a idade em que os jovens estarão ingressando no mercado de trabalho, ou darão prosseguimento em seus estudos, vislumbrando uma profissão técnica ou de nível superior. Entretanto, muitos desses jovens chegam a esta fase despreparados para a vida, pois o ensino médio continua a ser uma preparação para o vestibular, privilegiando aqueles que têm a chance de continuar com seus estudos, ao invés de ser a etapa final da educação básica, como preconizado pela LDB/96. O papel da investigação científica, como ferramenta de desconstrução do conhecimento, seria o de dar subsídios aos jovens para questionar, observar e decidir sobre seu futuro.

Tradicionalmente a ideia de se utilizar atividades experimentais na substituiçáo das aulas puramente teóricoexpositivas e ao mesmo tempo superar a falta de interesse na aprendizagem de ciências conta com uma larga tradição (LAZAROWITZ; TAMIR, 1994; LUNETTA, 1998). Axt (1991) argumenta que a experimentação contribui para uma melhor qualidade de ensino e que mesmo com algumas inserçôes de atividades experimentais no ensino brasileiro, desde a segunda metade do século passado, o ensino ainda é mais teórico do que experimental. Para esse autor, uma das principais dificuldades para adoção de atividades experimentais nas escolas é a falta de equipamentos e a impossibilidade de fazer reparos ou reposições nos já existentes.

“...de um modo geral, o ensino de ciências tem se realizado por meio de proposiçóes científicas, apresentadas na forma de definições, leis e princípios e tomados como verdades de fato, sem maior problematização e sem que se promova um diálogo mais estreito entre teorias e evidências do mundo real. Em tal modelo de ensino, poucas são as oportunidades de se realizar investigaçóes e de argumentar acerca dos temas e fenômenos em estudo. O resultado é que estudantes não aprendem conteúdos das Ciências e constroem representaçôes inadequadas sobre a ciência como empreendimento cultural e social." (MUNFORD e LIMA, 2007)
Estudantes de vários níveis escolares normalmente atribuem ao experimento a função de comprovar hipóteses e teorias (BADY, 1979). Em estudo realizado por Paula e Borges (2007) constatou-se que o laboratório escolar de fato é orientado para ilustrar fenômenos específicos que mostram se o comportamento de objetos e sistemas está em concordância com o que foi previsto por uma determinada lei ou teoria.

"Conceber testes experimentais para avaliar teorias ou explicaçóes requer que o estudante seja capaz de imaginar a aplicação da "teoria" ou do modelo a situaçóes específicas de modo a antever suas implicaçóes. Uma vez extraídas as implicaçóes, elas podem ser utilizadas para simular os fenômenos na mente, processo que produz previsóes susceptíveis de verificação experimental. Por um lado, esse exercício demanda conhecimento e o desenvolvimento da prática de modelamento por meio de atividades explicitamente voltadas para este propósito." (PAULA e BORGES, 2007 p. 185)

Segundo Pereira (2000), os objetivos do ensino de ciências seriam o desenvolvimento do pensamento lógico, a vivência do método científico, a universalidade das leis científicas, o conhecimento do ambiente e a sondagem de aptidóes e a preparação para o trabalho e a integração do indivíduo na sociedade. Nesse contexto, o ensino de física e ciências por meio da realização de experimentos, tendo o aluno como principal ator, auxiliaria no desenvolvimento de tais habilidades.

Com o objetivo de atrair o interesse dos alunos pela área de ciências e melhorar o rendimento dos mesmos em sala de aula, realizou-se um trabalho através da montagem de uma feira de ciências com os alunos do primeiro ano do ensino médio de uma escola pública da cidade de Resende, estado do Rio de Janeiro. O que será apresentado neste artigo é o relato do trabalho desenvolvido em sala de aula.

\section{METODOLOGIA}

O estudo foi desenvolvido em um colégio estadual de ensino médio do município de Resende, localizado no interior do Estado do Rio de Janeiro. A nível nacional, Resende está entre os 100 melhores municípios em PIB Total, em 80o lugar. A participação da Região do Médio Paraíba no volume arrecadado de IPI (Imposto sobre Produtos Industrializados) no Estado do Rio de Janeiro gira em torno de $10,9 \%$ no total arrecadado no Estado. A vocação industrial da região é favorecida pela boa infraestrutura rodoviária e localização privilegiada entre os dois maiores centros econômicos do país. Tudo isso contribui para que importantes empresas estejam presentes na regiāo e para que os jovens, 
ao concluirem o ensino médio, sejam absorvidos como mão-de-obra nestas indústrias.

A metodologia empregada foi qualitativa, buscando-se observar as reaçóes e o grau de envolvimento dos alunos durante o desenvolvimento dos experimentos.

O trabalho foi desenvolvido com seis turmas do primeiro ano do ensino médio, inserido na disciplina de atividades complementares. Essa disciplina tem como objetivos complementar, de forma menos formal, o ensino de ciências. Nessa escola, um tempo de aula semanal em cada série era designado para disciplina citada anteriormente, sendo subordinada às disciplinas de física no primeiro ano, de química no segundo ano, e de biologia no terceiro ano.

O projeto conseguiu envolver toda a escola, direta ou indiretamente. As seis turmas do primeiro ano participaram das atividades de montagem da feira de ciências e as demais turmas do colégio assistiram às apresentaçôes dos alunos.

O trabalho foi dividido em duas etapas: a primeira envolveu pesquisa de experimentos relacionados à disciplina de física ou de química em livros e na internet; a segunda fase foi a realização da experiência e confecção de material explicativo, culminando com a exposiçấo e apresentação dos trabalhos para os alunos do colégio. O tempo utilizado para o desenvolvimento das duas etapas foi de 45 dias.

\section{RESULTADOS E OBSERVAÇÓES DOS ALUNOS}

Após a escolha do tema, os alunos montaram as experiências e confeccionaram cartazes explicativos, contendo uma breve explicação teórica e as etapas do desenvolvimento da mesma. Dentre os temas escolhidos, destacam-se: densidade, conceitos variados de pressão, telégrafo, transferência de calor, eletricidade.

Os trabalhos foram expostos por cada turma na respectiva sala de aula, pois o colégio não dispóe de um local onde todos pudessem expor os trabalhos ao mesmo tempo. Por este motivo, em cada turma, os temas dos trabalhos não podiam se repetir, mas podiam ser apresentados os mesmos temas em outras turmas. Isso foi feito para se verificar diferentes maneiras de se explicar a mesma teoria. O que será relatado a seguir consiste em uma das experiências que foi demonstrada por grupos de três turmas diferentes.

A experiência em questão é "O ovo que afunda e o ovo que flutua”, que foi retirada pelos alunos de sites na internet (MARS, 2008; CIÊNCIA PARA CRIANÇAS, 2008) e está descrita em anexo. A experiência aborda a questáo da densidade, como foi proposta, mas também permite explicar sobre líquidos imiscíveis (EXPLICATORIUM, 2008) e sobre empuxo, dependendo de como seja feita a abordagem por parte do grupo.

Nenhum dos grupos conseguiu visualizar o conceito de empuxo na experiência, provavelmente por não terem conhecimento, ainda, desse conceito físico. Apenas um dos alunos do segundo ano, enquanto visitava os trabalhos expostos conseguiu relacionar a experiência do ovo com o conceito de empuxo e comentou: "Poxa, o ovo flutua devido à questão do empuxo que o meu professor explicou”. Essa observação demonstra que a experiência foi capaz de levar este aluno a relacionar os dois conceitos, densidade do líquido com empuxo, ou seja, fez uma relação do conceito teórico com a prática exposta.

Os alunos que participaram da feira de ciências, como expositores e/ou visitantes elogiaram os trabalhos dos colegas e conseguiram visualizar vários conceitos já aprendidos em sala de aula e outros que ainda serão transmitidos posteriormente. Como afirma Francisco Jr et al (2008) “... só é possível explicar um fenômeno a partir do momento em que este seja pessoalmente significativo, a partir do momento em que a curiosidade seja despertada nos estudantes. Esse é o papel motivador da experimentação...”.Alguns dos comentários dos alunos participantes da feira e ciências:

"Foi muito legal montar a experiência e o melhor é que deu certo!"

"A experiência que eu mais gostei foi a da carta mágica feita com limão, da menina da turma 1003."

"A experiência do meu grupo me ajudou a ver a explicação da professora sobre como o calor passa através de uma barra de metal."

"Pena que a minha turma não participou do projeto!!!!"

Durante o restante do ano letivo, terceiro e quarto bimestres, o interesse dos alunos pela disciplina melhorou e as notas na disciplina de Física passaram de $45 \%$ para $70 \%$ de alunos com média maior ou igual a cinco.

"Diversificar os ambientes de aprendizagem favorece que todos os alunos 'entrem na roda', produzam e aprendam conhecimento físico, dentro de uma dinâmica com a qual se identifiquem mais. Nossa aposta é que, ao participar de um ambiente onde se sinta bem, expressando e desenvolvendo seus potenciais de aprendizagem, o aluno se abra para o restante da programação proposta em um curso de física. Aquela expressão 'odeio física' pode estar fundada no sentimento permanente de fracasso e na sensaçáo, por parte do aluno, de que não é capaz de aprender nada dessa área de conhecimento.” (MOREIRA e BORGES, 2006)

As experiências realizadas pelos alunos poderiam também ser empregadas em sala de aula como demonstraçáo de um fenômeno por parte do professor, "podendo contribuir para a compreensão de diversos aspectos relacionados ao mesmo" (ARAÚJO e ABIB, 2003). Segundo observado por Carrascosa et al (2006) professores e alunos avaliam de forma positiva o enfoque das práticas de laboratório como investigaçôes. 


\section{CONCLUSÔES}

Os objetivos do trabalho foram atingidos, uma vez que o interesse e o rendimento dos alunos na disciplina de Física aumentaram significativamente.

A experimentação no ensino de ciências mostrou-se aplicável às aulas do ensino médio, sem a necessidade da existência de um laboratório ou de equipamentos sofisticados. O papel da experimentação com participação dos alunos foi eficaz para incentivar a curiosidade dos discentes, para mobilizar o trabalho em grupo e para despertar o questionamento científico.

\section{REFERÊNCIAS}

ARAÚJO, Mauro Sérgio Teixeira de Araújo, ABIB, Maria Lúcia Vital dos Santos. Atividades Experimentais no Ensino de Física: Diferentes Enfoques, Diferentes Finalidades. Revista Brasileira de Ensino de Física, v. 25, n. 2, p. 176-194, 2003.

AXT, R. O papel da experimentaçáo no ensino de ciências. In: MOREIRA (ORG). Tópicos em Ensino de Ciências. Pará: Sagra, 1991.

BADY, R. J. Student's understanding of the logic of hypothesis testing. Journal of Research Science Teaching, v. 16, n. 1, p. 61-65, 1979.

CARrascoSA, J., PÉREZ, D.G., VILCHES, A. Papel de la actividad experimental en la Educación científica. Caderno Brasileiro de Ensino de Física, v. 23, n. 2, p. $157-$ $181,2006$.

CHINN, C; MALHOTRA, B.A. Epistemologically authentic inquiry in schools: A theoretical framework for evaluating inquiry tasks. Science Education, n.86, p.175218, 2002.

CIÊNCIA PARA CRIANÇAS. O ovo que flutua e o ovo que afunda. Disponível em: < http://www.bioqmed.ufrj. br/ciencia/Ovo3.htm>Acesso em: 23 jun. 2008.

EXPLICATORIUM. Flutuo ou afundo ? Disponível em <http://www.explicatorium.com/Laboratorio-aberto.php > Acesso em: 20 jun. 2008.
FRANCISCO Jr, W. E., FERREIRA, L. H., HARTWIG, D. R. Experimentaçáo Problematizadora: Fundamentos Teóricos e Práticos para a Aplicaçáo em Salas de Aula de Ciências. Química Nova na Escola, n.30, p.34-41, 2008.

LAZAROWITZ, R.; TAMIR, P. Research on using laboratory instruction in science. In: GABEL, D. (Ed.). Handbook of Research on Science Teaching and Learning. New York: McMillan Pub Co., 1994.

LUNETTA, V. The school science laboratory: historical perspectives and contexts for contemporary teaching. En: FRASER, B.; TOBIN, K. (Eds.). International Handbook of Science Education. London: Kluwer Academic Publishers, p. 249- 262, 1998.

MARS. Será que o ovo flutua? Disponível em: <http:// mars.fis.uc.pt/ $\sim \mathrm{cp} / \mathrm{cab} /$ dterra/node12.html $>$ Acesso em: 25 jun. 2008 .

MOREIRA, A.F., BORGES, O. Por dentro de uma sala de aula de física. Educação e Pesquisa, v.32, n.1, p. 157 174, 2006

MUNFORD, D. E LIMA, M.E.C.C. Ensinar ciências por investigação: em quê estamos de acordo? Ensaio - Pesquisa em educação em ciências, v.9, n.1, 2007. Disponível em: <http://www.fae.ufmg.br/ensaio/v9_n1/ensinar-cienciaspor-investigacao_m-emilia-e-danusa.pdf> Acesso e: $25 \mathrm{fev}$. 2009.

PAULA, H.F. E BORGES, A.T. Avaliaçáo e teste de explicaçóes na educaçáo em ciências. Ciência \& Educação, v. 13, n. 2, p. 175-192, 2007.

PEREIRA, A. B.; OAIGEN, E.R.; HENNIG.G. Feiras de Ciências. Canoas: Ulbra, 2000.

RICARDOL, E.C. E FREIRE, J.C.A. A concepção dos alunos sobre a física do ensino médio: um estudo exploratório. Revista Brasileira de Ensino de Física, v. 29, n. 2, p. 251-266, 2007. Disponível em: <www.sbfisica.org.br> Acesso em: 02 mar. 2009.

VYGOTSKY, L.S. A construçáo do pensamento e da linguagem. São Paulo: Editora Martins Fontes, 2001. 


\section{ANEXO}

"O ovo que afunda e o ovo que flutua!" (adaptado de BIO-

QMED, 2008)

O que você precisa:

- 2 ovos crus

- 2 copos transparentes

- água

- sal

O que fazer:

1. Marque cada um dos copos, usando uma caneta para retroprojetor ou um pedaço de fita crepe, "com sal" e "sem sal".

2. Encha os dois copos com a mesma quantidade de água. Coloque uma quantidade de água suficiente para cobrir bem um ovo. Em um dos copos, adicione 2 colheres de sal e mecha bem até dissolver.

3. Coloque um ovo dentro de cada um dos copos. O que aconteceu?

O que está acontecendo:

$\mathrm{O}$ ovo tem uma densidade maior que a água sem sal e afunda. Quando você adicionou sal à água, a densidade da água mudou. A água com sal é mais densa que a água sem sal!

Densidade é uma relação entre massa e volume. Se usarmos o mesmo volume de água nos dois copos e, depois de dissolver bem o sal em um deles, o volume náo variou, no copo que tem sal, temos mais massa (água + sal) que no copo sem sal (só água). Ou seja, a água com sal tem mais massa que a mesma quantidade de água sem sal e, por isso, é mais densa. 